\title{
Neurotoxic Risk Caused by Stable and Variable Exposure to Methylmercury From Seafood
}

\section{Citation}

Grandjean, Philippe, Roberta F. White, Pal Weihe, and Poul J. Jørgensen. 2003. "Neurotoxic risk caused by stable and variable exposure to methylmercury from seafood." Ambulatory Pediatrics 3, no. 1 (2003): 18-23.

\section{Published Version}

10.1367/1539-4409(2003)003<0018:NRCBSA>2.0.CO;2

\section{Permanent link}

http://nrs.harvard.edu/urn-3:HUL.InstRepos:34787262

\section{Terms of Use}

This article was downloaded from Harvard University's DASH repository, and is made available under the terms and conditions applicable to Other Posted Material, as set forth at http:// nrs.harvard.edu/urn-3:HUL.InstRepos:dash.current.terms-of-use\#LAA

\section{Share Your Story}

The Harvard community has made this article openly available.

Please share how this access benefits you. Submit a story.

\section{Accessibility}


Manuscript to be published in Ambulatory Pediatrics

\section{Neurotoxic Risk Caused by Stable and Variable Exposure}

\section{to Methylmercury from Seafood}

Grandjean, Philippe MD, PhD*ł; White, Roberta F. PhD*+; Weihe, Pal MD* ; Jørgensen, Poul J. MScll

From the *Institute of Public Health, University of Southern Denmark, Odense, Denmark;

$\ddagger$ Departments of Environmental Health and Neurology, Boston University Schools of Medicine and Public Health, Boston, Massachusetts; §Department of Occupational and Public Health, Faroese Hospital System, Torshavn, Faroe Islands; and IIOdense University Hospital, Odense, Denmark.

Reprint requests to (P.G.) Department of Environmental Medicine, University of Southern Denmark, Winslowparken 17, DK-5000 Odense, Denmark.

E-mail: pgrand@health.sdu.dk

Supported by the U.S. National Institute of Environmental Health Sciences (ES06112 and ES 09797), the European Commission (Environment Research Programme), and the Danish Medical Research Council. The contents of this paper are solely the responsibility of the authors and do not represent the official views of the NIEHS, NIH or any other funding agency. 
AbSTRACT

Objectives. To examine whether the dose-effect relationship for developmental mercury neurotoxicity is affected by variable mercury exposure during pregnancy. Methods. The study was based on a birth cohort of 1022 children born in the Faroe Islands from March 1986 to December 1987. Neurobehavioral performance of 917 children (90\%) was assessed at age 7. Intrauterine methylmercury exposure was determined from mercury concentrations in cord blood and two sets of maternal hair. Complete exposure information was available for 614 (67\%) children.

Results. In children with complete exposure data, eight of sixteen neuropsychological tests showed deficits significantly associated with the cord-blood mercury concentration after confounder adjustment. Variable intrauterine exposure was suggested by disagreement between mercury concentrations in the two maternal hair samples. Removal of the $61(10 \%)$ of the children with the greatest degree of variable exposure had a minimal effect on most exposureeffect relationships. However, the effect of the cord-blood concentration on verbal learning and memory was greater after this exclusion.

Conclusion. The study supports previous findings from this cohort study that maternal mercury exposure during pregnancy is associated with neuropsychological deficits detectable at age 7 years and that this association is evident in women with stable exposures throughout pregnancy and thus not due to variable exposures.

ABBREVIATIONS. Hg, mercury; MeHg, methyl mercury Methylmercury $(\mathrm{MeHg})$ is a neurotoxicant which accumulates in seafood and freshwater fish. ${ }^{1}$ Because of the worldwide occurrence of this pollutant, concerns about the health implications 
have spurred detailed risk assessments. ${ }^{1,2}$ The risks to human health were demonstrated in a poisoning incident in Iraq, where MeHg-treated grain was inadvertently used for bread-making. ${ }^{3}$ The most serious neurological deficits were observed in children whose mothers were pregnant during the exposure. ${ }^{3}$ In developing the dose-response relationship for this incident, researchers used as the exposure indicator the peak mercury $(\mathrm{Hg})$ concentration observed in 1-cm segments of maternal hair grown during the pregnancy period. ${ }^{4}$

While analysis of a hair sample for $\mathrm{Hg}$ is an easy way of obtaining an exposure estimate, ${ }^{5}$ segmental analysis of hair strands to determine short-term exposure variations would not be practical in large-scale studies. Such detailed exposure assessment may not be necessary for dietary exposures in fishing communities, where exposures would vary much less than during a poisoning incident. Still, theoretical calculations show that a large meal of contaminated seafood could cause a relative change in the hair-Hg concentration that may not be negligible. ${ }^{6}$ The impact of such meals is smoothed by the sustained retention of $\mathrm{MeHg}$ in the body (the biological half-life of $\mathrm{MeHg}$ is thought to be approximately 1.5 months $^{7}$ ). In addition, any short-term peak absorption levels resulting from variations in maternal diet may be moderated by placental passage so that they become less marked in the fetal circulation.

Evaluation of this issue is complicated because the time of a peak exposure must be considered in relation to vulnerable periods of brain development. ${ }^{8}$ At the same time, the implications of temporal differences in susceptibility must be considered in light of the persistence of $\mathrm{MeHg}$ in the body. The cord-blood $\mathrm{Hg}$ concentration has been found to be the best available predictor of deficits on several neurobehavioral outcome parameters. ${ }^{9-11}$ This biomarker appears to be advantageous, because it reflects the amount of $\mathrm{MeHg}$ that has penetrated into the 
fetal circulation, and it also indicates exposures occurring late in gestation, when most cognitive functions appear to be particularly vulnerable. ${ }^{8}$ However, for outcome variables sensitive to exposures during the early part of the gestation, the $\mathrm{Hg}$ concentration present in cord blood at the time of parturition could be a poor risk indicator if the exposure has been variable.

Several biomarkers of exposure are available from a prospective study of developmental $\mathrm{MeHg}$ neurotoxicity carried out in the Faroe Islands. ${ }^{12}$ In addition to the Hg concentration in cord blood, we also analyzed two sets of maternal hair samples. One full-length sample collected at the time of parturition reflected the average $\mathrm{MeHg}$ exposure during the pregnancy period. ${ }^{13}$ In addition, a segment close to the scalp has now been analyzed to document the exposures closer in time to the parturition. ${ }^{14}$ Although differences in hair growth rates, certain types of hair treatment, and other factors may affect $\mathrm{Hg}$ deposition in hair, ${ }^{15}$ concordance between the $\mathrm{Hg}$ concentrations in the two samples would suggest a rather stable exposure during the pregnancy period. Thus, these results may be used to determine the neurobehavioral implications of stable versus variable intrauterine $\mathrm{MeHg}$ exposure levels.

\section{METHODS}

\section{Participants}

A birth cohort was generated in 1986-1987 at the three hospitals in the Faroe Islands. MeHg exposure in this population originates from pilot whale meat and certain kinds of fish and seabirds. As the major source of exposure, the whale meat contains a relatively high $\mathrm{MeHg}$ concentration. ${ }^{16}$ It is most often eaten as thin slices of cured meat, but a large steak of uncured whale meat could possibly cause a substantial peak exposure. Because the crude dietary 
questionnaire on maternal food habits during pregnancy ${ }^{13}$ did not allow a detailed assessment on dietary exposure patterns, biomarkers were used to characterize individual levels and changes in exposure during pregnancy. For this purpose, both cord blood and maternal hair were sampled at parturition and subsequently analyzed for $\mathrm{Hg}$.

\section{Methylmercury exposure assessment}

Prenatal exposure to $\mathrm{MeHg}$ was determined from analysis of the total $\mathrm{Hg}$ concentration in cord blood by cold-vapor atomic absorption. ${ }^{13}$ Hair samples corresponding to the full duration of pregnancy were analyzed to obtain a measure of the average exposure. ${ }^{13}$ In addition, remaining hair samples have now been reanalyzed to obtain the $\mathrm{Hg}$ concentration in the proximal $2 \mathrm{~cm} .{ }^{14}$ Assuming that a lag time of 5-6 weeks is not covered by the hair sample when cut close to the

scalp and also assuming a hair growth rate of $1 \mathrm{~cm}$ per month, ${ }^{2}$ the proximal 2 -cm segment will have been formed and will have incorporated circulating mercury during weeks 27-35 of a term pregnancy. Using a biological half-life of 45 days for $\mathrm{MeHg}$ in the body, ${ }^{7}$ the relative contribution of dietary $\mathrm{MeHg}$ intakes to the $\mathrm{Hg}$ concentration in this segment can then be estimated (Fig. 1). For the full-length hair samples, more than two-thirds were $8-9 \mathrm{~cm}$ and only $5 \%$ were less than $5 \mathrm{~cm}$ long. In this case, $\mathrm{MeHg}$ intakes during the early part of the pregnancy would contribute relatively more to the $\mathrm{Hg}$ concentration measured (Fig. 2). All results are given in $\mu \mathrm{g} / \mathrm{g}$ and can be converted to nmol/g by multiplying by a conversion factor of 5.0 .

\section{Neuropsychological assessment}

At age 7 years, 917 (90\%) of the cohort members participated in a thorough clinical examination 
with focus on nervous system function. ${ }^{9}$ Neuropsychological tests were chosen to include tasks that would be affected by the neuropathological abnormalities described in congenital $\mathrm{MeHg}$ poisoning and the functional deficits seen in children with early-life exposure to other neurotoxicants. ${ }^{17}$ Paper-and-pencil tests were administered by a Faroese clinical psychologist who had translated the tests into Faroese and verified their feasibility through pilot testing of Faroese children. Three computer-assisted tests were given at a separate session using the same portable computer with the recommended joy-stick. Each child was asked about familiarity with computer games, and the answer was scored as none, some and much. The individual tests are shown in Table 1.

\section{Statistical analysis}

Regression equations were calculated for the 614 children (67\%) who had both hair-Hg assessments available. If maternal $\mathrm{MeHg}$ intake had been rather constant during the pregnancy period, the two hair samples would show identical $\mathrm{Hg}$ concentrations. Indeed, the results were rather similar for most of the children. ${ }^{14}$ To determine the effect of removing subjects with a variable exposures during pregnancy, we excluded the children with the greatest relative difference in $\mathrm{Hg}$ concentrations in the two analyses of maternal hair. The cord-blood $\mathrm{Hg}$ concentration was used as the independent exposure variable in all analyses, as previously described. ${ }^{9}$ Because of skewed distributions, logarithmic transformation of the mercury concentrations was used. A standard set of eight confounders (age, sex, medical risk factors, maternal intelligence, maternal and education, paternal employment, and day care) were included for adjustment of all outcome variables, and computer experience was added for the computer- 
assisted tests.

\section{RESULTS}

The three exposure biomarkers correlated well (Table 2). As expected, the result from the proximal hair segment correlated slightly better with the cord blood concentration than did the full-length hair sample. The two hair $\mathrm{Hg}$ results were in good agreement in most cases (Fig.3). However, in $10 \%$ of the cases $(\mathrm{N}=59)$, the smaller concentration of the two was less than $60 \%$ of the higher one, a difference substantially exceeding the analytical imprecision. These subjects were therefore considered to have had a variable exposure.

Exclusion of children with the two hair-Hg parameters suggesting variable exposure improved the correlation between the two hair concentrations $(r=0.96)$, but barely affected their associations with the cord-blood concentration (0.82 and 0.79 , respectively, after exclusion).

Table 3 shows the test performance in children from whom two maternal hair-Hg analyses were available. These results and the association with the cord-blood $\mathrm{Hg}$ concentration are quite similar to those obtained from the cohort as a whole, ${ }^{9}$ i.e., before exclusion of children with only one hair-Hg assessment. All regression coefficients indicate a poorer performance at higher prenatal MeHg exposure levels, and eight of them are statistically significant at a twosided 5\% limit.

In general, exclusion of the children with variable exposure did not materially affect the regression coefficients for $\mathrm{Hg}$ (Table 3). However, almost all verbal tests suggest a stronger $\mathrm{Hg}$ effect after the exclusion. In a previous report, ${ }^{9}$ a single test with the best psychometric properties had previously been selected to reflect each of five modalities of brain function (motor speed, 
attention, visuospatial, language and verbal memory). For all of these tests, i.e., Finger Tapping with preferred hand, CPT reaction time, copying errors on Bender test, Boston Naming score after cues, and short-term recall on CVLT, the numerical size of the regression coefficient increased, by $3 \%$ to $43 \%$.

Similar calculations were carried out with the proximal hair- $\mathrm{Hg}$ concentration as the independent variable (data not shown). In general, the regression coefficients were lower for this exposure biomarker than for the cord-blood $\mathrm{Hg}$ concentration in accordance with previous findings. ${ }^{12}$

\section{DISCUSSION}

Dose-effect relationships for developmental neurotoxicity in children must consider the validity

of the biomarkers of exposure. ${ }^{23}$ In observational studies, intakes of food contaminants are bound to vary somewhat, even in subjects who stick to a regular diet. Such temporal variations will affect the exposure biomarker result as well as the dose that reaches the target tissue, though not necessarily the same way. Thus, when the exposure is variable, the imprecision of the exposure measure will tend to increase, thereby also decreasing the likelihood of detecting a true exposureassociation. This bias toward the null hypothesis will result in lower regression coefficients and higher $\mathrm{p}$ values.

With MeHg neurotoxicity, concerns have also been raised regarding the role that peaks and troughs in exposure may play in the appearance of neurotoxic damage. Accordingly, the average exposure level may not be a precise risk indicator; under acute exposure conditions, the peak exposure level seems to provide a meaningful risk estimate. ${ }^{4}$ Although peaks early and late 
in gestation are unlikely to have the same impact on brain development, risk assessment efforts have not taken this factor into consideration. ${ }^{1,24}$ Exposures in fishing communities with a steady supply of seafood would probably be rather stable, but segmental hair analyses of Faroese samples have shown that some variation occurs, sometimes with coefficients of variation above $20 \%$, i.e., clearly exceeding the laboratory imprecision. ${ }^{14}$ The significance of exposure variations for neurotoxic risks may therefore also apply to such settings, although clearly to a much lesser extent than in the previously described poisoning incident. ${ }^{3,4}$

Temporal patterns of exposure variations may be important because of changes in vulnerability at different stages of prenatal brain development. ${ }^{8}$ Thus, Fig. 3 shows that some mothers had an increased $\mathrm{Hg}$ concentration in the proximal hair segment corresponding to exposures late in pregnancy, while others had a greater exposure earlier on, as indicated by a higher average concentration in the full-length hair sample. However, due to limited number of such divergent cases, the present study is not informative with regard to the timing of vulnerability. Also, the smoothing effect of the $\mathrm{MeHg}$ persistence in the body would tend to decrease the impact of exposure variations.

The exclusion of children with the greatest variation in exposure resulted in minor changes in mercury regression coefficients (Table 3), thus suggesting only a limited impact of peaks and troughs that were large enough to be identified this way. However, the main direction of the changes suggested a stronger mercury effect after exclusion of the children with the greatest variations in exposure. This finding is in accordance with the expectation of a bias toward the null hypothesis cause by exposure misclassification.

Some morphologic features of the brain are well developed by the end of the second 
trimester. However, processes such as neuronal migration and synapse continue during the third trimester and are crucial to functional development. ${ }^{8}$ Thus, as a biomarker dependent on neurotoxicant doses received during recent weeks, the $\mathrm{Hg}$ concentration in cord blood at the time of parturition is probably the best available risk indicator. ${ }^{14}$ The fact that exposure variations earlier in pregnancy, as documented by the hair analyses, only slightly affected the cord-blood $\mathrm{Hg}$ regression coefficients for relevant outcomes supports the validity of this biomarker. Still, different brain functions may well differ in their temporal profile of vulnerability to a neurotoxicant such as $\mathrm{MeHg}$ and it is possible that the functional domains examined are subsisted by brain structures with differing vulnerability periods.

While studies in other communities have also shown $\mathrm{Hg}$-associated neurotoxicity in children, ${ }^{25-29}$ a prospective study in the Seychelles ${ }^{30}$ has not so far shown any definite signs of adverse health effects. Although the outcome variables examined in the latter study may not have been sufficiently sensitive,${ }^{31}$ another important difference between the studies was that the exposure assessment in the Seychelles was based on $\mathrm{Hg}$ concentrations in maternal hair samples obtained up to 6 months after delivery. ${ }^{32}$

The Reference Dose defined by the U.S.EPA ${ }^{1}$ corresponds to a hair-Hg concentration of about $1 \mu \mathrm{g} / \mathrm{g}$, i.e., a level substantially below the average seen in the Faroese birth cohort. Based on the most recent estimates from US studies, the National Research Council committee estimated that over 60,000 births may be occurring annually in which the limit is exceeded. ${ }^{2}$ Hair analyses may therefore be indicated in population groups with a high intake of freshwater fish and marine food, whether or not peak exposures from species with high $\mathrm{Hg}$ concentrations are likely. 
CONCLUSION

The study supports previous findings from the Faroese cohort that maternal $\mathrm{MeHg}$ exposure during pregnancy is associated with neuropsychological deficits detectable at age 7 years. Exclusion of children with variable intrauterine exposure levels between early and late pregnancy caused only a slight change, mainly an increase, in the mercury-association of the deficits. The reported associations with adverse effects therefore seem not to be due to peak exposures. Rather, if some outcome variables are affected by peak exposures early in pregnancy, exposure variability may have resulted in an underestimation of $\mathrm{MeHg}$ effects sensitive to exposures early in pregnancy. Accordingly, the cord-blood $\mathrm{Hg}$ concentration remains the most valid risk indicator. 


\section{REFERENCES}

1. Mercury Study Report to Congress. Washington, D.C.: U.S. Environmental Protection Agency, 1997.

2. National Research Council. "Toxicological Effects of Methylmercury”. National Academy Press, Washington, DC, 2000.

3. Amin-Zaki L, Elhassani S, Majeed MA, Clarkson TW, Doherty RA, Greenwood M. Intra-uterine methylmercury poisoning in Iraq. Pediatrics 1974; 54: 587-95.

4. Marsh DO, Clarkson TW, Cox C, Myers GJ, Amin-Zaki L, Al-Tikriti S. Fetal methylmercury poisoning. Relationship between concentration in single strands of maternal hair and child effects. Arch Neurol 1987; 44: 1017-22.

5. Grandjean P, Weihe P, Nielsen JB. Methylmercury: Significance of intrauterine and postnatal exposures. Clin Chem 1994; 40: 1395-1400.

6. Ginsberg GL, Toal BF. Development of a single-meal fish consumption advisory for methyl mercury. Risk Anal 2000; 20: 41-7.

7. Smith JC, Farris FF. Methyl mercury pharmacokinetics in man: a reevaluation. Toxicol Appl Pharmacol 1996; 137: 245-52.

8. Dobbing J. Vulnerable periods in developing brain. In: Davison AN, Dobbing J, Eds. Applied Neurochemistry. Davis, Philadelphia, 1968, pp. 287-316.

9. Grandjean P, Weihe P, White RF, Debes F, Araki S, Murata K, Sørensen N, Dahl D, Yokoyama K, Jørgensen PJ. Cognitive deficit in 7-year-old children with prenatal exposure to methylmercury. Neurotoxicol Teratol 1997; 19: 417-28.

10. Sørensen N, Murata K, Budtz-Jørgensen E, Weihe P, Grandjean P. Blood pressure and 
heart rate in 7-year-old children with prenatal exposure to methylmercury. Epidemiol 1999; 10: 370-5.

11. Murata K, Weihe P, Araki S, Budtz-Jørgensen E, Grandjean P. Evoked potentials in Faroese children prenatally exposed to methylmercury. Neurotoxicol Teratol 1999; 21: $471-2$.

12. Grandjean P, Budtz-Jørgensen E, White RF, Jørgensen PJ, Weihe P, Debes F, Keiding N. Methylmercury exposure biomarkers as indicators of neurotoxicity in 7-year-old children. Am J Epidemiol 1999; 150: 301-5.

13. Grandjean P, Weihe P, Jørgensen PJ, Clarkson T, Cernichiari E, Viderø T. Impact of maternal seafood diet on fetal exposure to mercury, selenium, and lead. Arch Environ Health 1992; 47: 185-95.

14. Grandjean P, Jørgensen PJ, Weihe P. Validity of mercury exposure biomarkers. Prog Nucleic Acid Res Mol Biol (in press).

15. Suzuki T. Hair and nails: advantages and pitfalls when used in biological monitoring. In Clarkson TW, Friberg L, Nordberg GF, Sager PR, eds. Biological monitoring of toxic metals. New York: Plenum, 1988, pp. 623-40.

16. Andersen A, Juhlshamn K, Ringdal O, Mørkøre J. Trace elements intake in the Faroe Islands II. Intake of mercury and other elements by consumption of pilot whales (Globicephalus meleanus). Sci Total Environ 1987; 65: 63-8.

17. White RF, Debes F, Dahl R, Grandjean P. Development and field testing of a neuropsychological test battery to assess the effects of methylmercury exposure in the Faroe Islands. In: Proceedings of the International Symposium on Assessment of Environmental 
Pollution and Health Effects of Methylmercury. University of Kumamoto, Kumamoto, Japan, 1994, pp. 127-40.

18. Letz R, Baker EL. NES2, neurobehavioral evaluation system manual. Winchester, MA: Neurobehavioral Systems, 1988.

19. Wechsler D. Wechsler intelligence scale for children-revised. New York: Psychological Corp, 1974.

20. Schlange H, Stein B, von Boetticher I, Taneli S. Göttinger Formreproduktions-Test. Göttingen: Verlag für Psychologie, 1977.

21. Kaplan E, Goodglass H, Weintraub S. The Boston naming test. Philadelphia: Lea and Febiger, 1983.

22. Delis DC, Kramer JH, Kaplan E, Ober BA. California verbal learning test (children). San Antonio: Psychological Corp, 1994.

23. Grandjean P. Biomarkers in epidemiology. Clin Chem 1995; 41: 1800-3.

24. Crump K, Viren J, Silvers A, Clewell H, Gearhart J, Shipp A. Reanalysis of dose-response data from the Iraqi methylmercury poisoning episode. Risk Anal 1995; 15: 523-32.

25. Kjellström T, Kennedy P, Wallis S. Physical and mental development of children with prenatal exposure to mercury from fish. Stage 2, interviews and psychological tests at age 6. (Report 3642) Stockholm: National Swedish Environmental Protection Board, 1989.

26. Grandjean P, White RF, Nielsen A, Cleary D, de Oliveira Santos EC. Mercury neurotoxicity in Amazonian children downstream from gold mining. Environ Health Perspect 1999; 107: 587-91. 
27. Murata K, Weihe P, Renzoni A, Debes F, Vasconcelos R, Zino F, Araki S, Jørgensen PJ, White RF, Grandjean P. Delayed evoked potentials in Madeiran children exposed to methylmercury from seafood. Neurotoxicol Teratol 1999; 21: 343-8.

28. Steuerwald U, Weihe P, Jørgensen PJ, Bjerve K, Brock J, Heinzow B, Budtz-Jørgensen E, Grandjean P. Maternal seafood diet, methylmercury exposure, and neonatal neurological function. J Pediatr 2000; 136: 599-605.

29. Cordier S, Garel M, Amiel-Tison C, Morcel H, Mandereau L. Neurologic and neurodevelopment investigations of methylmercury-exposed children in French Guinea. Epidemiol. 10: S102; 1999.

30. Davidson PW, Myers GJ, Cox C, Axtell C, Shamlaye C, Sloane-Reeves J, Cernichiari E, Needham L, Choi A, Wang Y, Berlin M., Clarkson TW. Effects of prenatal and postnatal methylmercury exposure from fish consumption on neurodevelopment: outcomes at 66 months of age in the Seychelles Child Development Study. J Am Med Assoc 1998; 280 : 701-07.

31. Mahaffey KR. Methylmercury exposure and neurotoxicity (editorial). J Am Med Assoc 1998; 280: 737-8.

32. Cernichiari E, Toribara TY, Liang L, Marsh DO, Berlin MW, Myers, GJ, Cox C, Shamlaye CF, Choisy O, Davidson P. The biological monitoring of mercury in the Seychelles study. Neurotoxicology 1995; 16: 613-28. 
Fig. 1. Relative contribution by $\mathrm{MeHg}$ exposures during pregnancy to the $\mathrm{Hg}$ concentration in a 2-cm proximal hair segment sampled at the time of parturition and assuming a biological halflife for MeHg of 45 days. 


\section{Proximal $2 \mathrm{~cm}$}

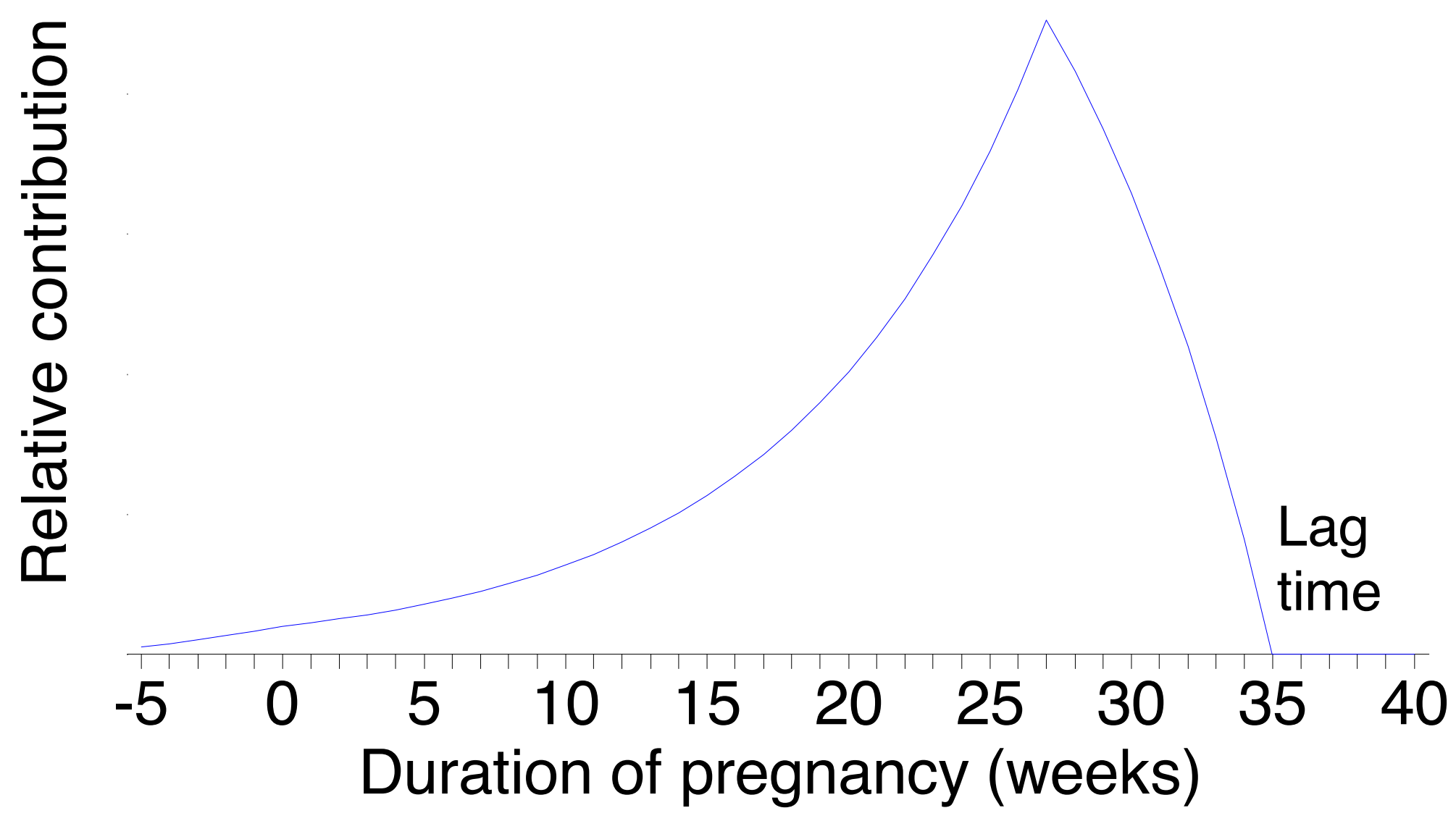


Fig. 2. Relative contribution by $\mathrm{MeHg}$ exposures during pregnancy to the $\mathrm{Hg}$ concentration in an 8-cm (full-length) hair sample obtained at the time of parturition and assuming a biological halflife for $\mathrm{MeHg}$ of 45 days. 


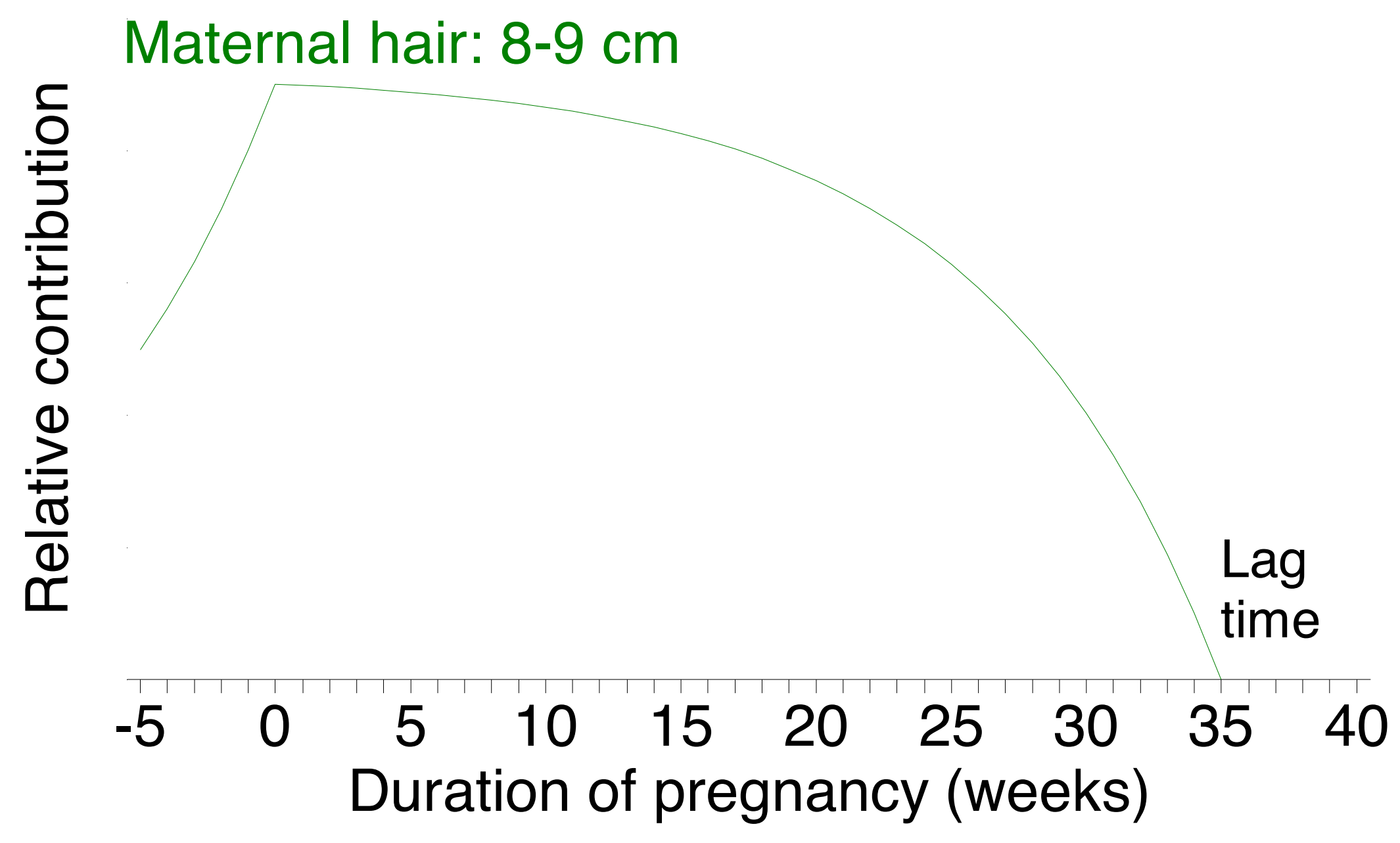


Fig. 3. $\mathrm{Hg}$ concentration in paired sets of proximal and full-length hair samples $(\mu \mathrm{g} / \mathrm{g})$. The $10 \%$ of samples with the greatest relative disconcordance between the two measurements are indicated with open circles. 


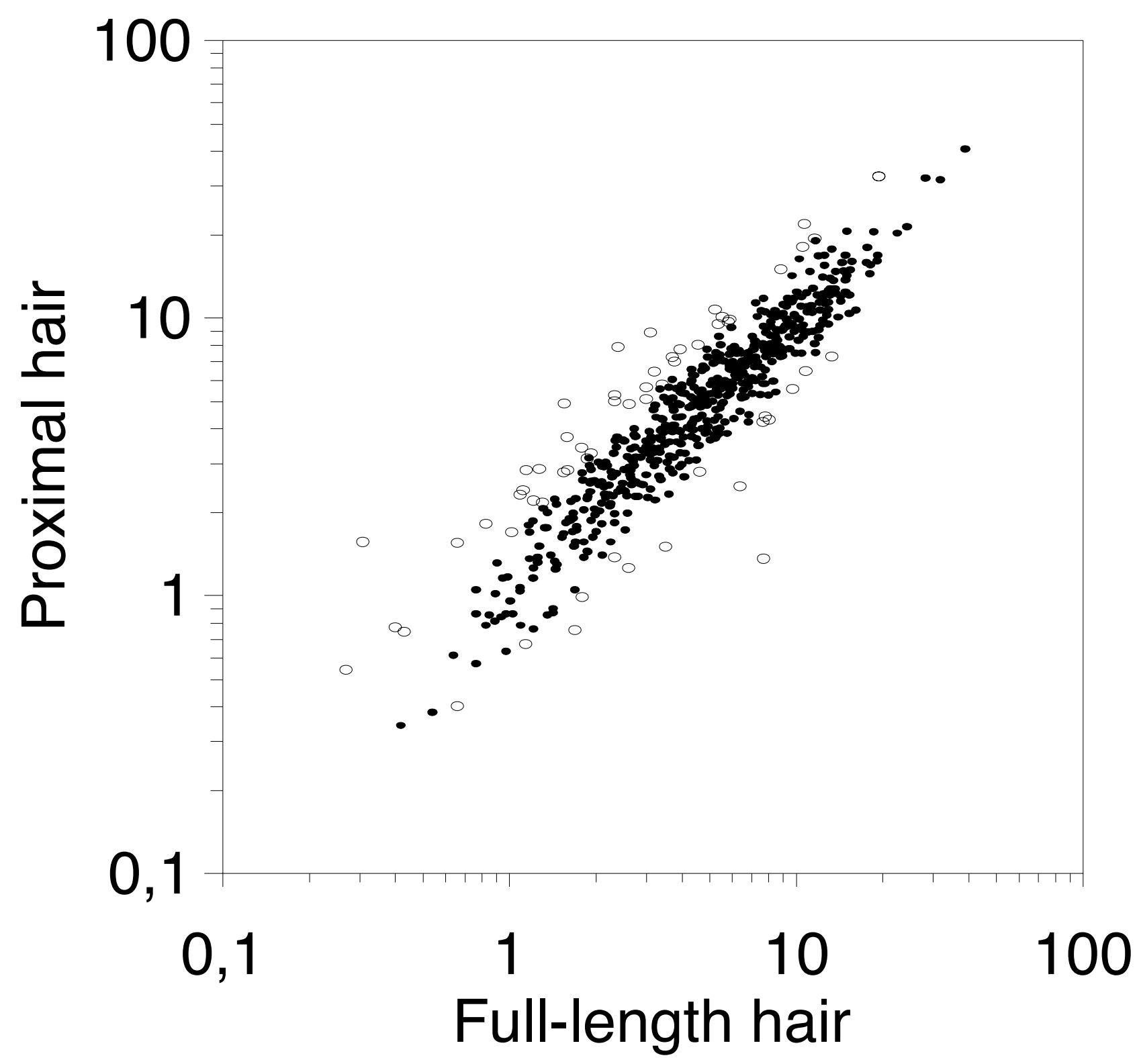


TABLE 1. Neuropsychological tests used

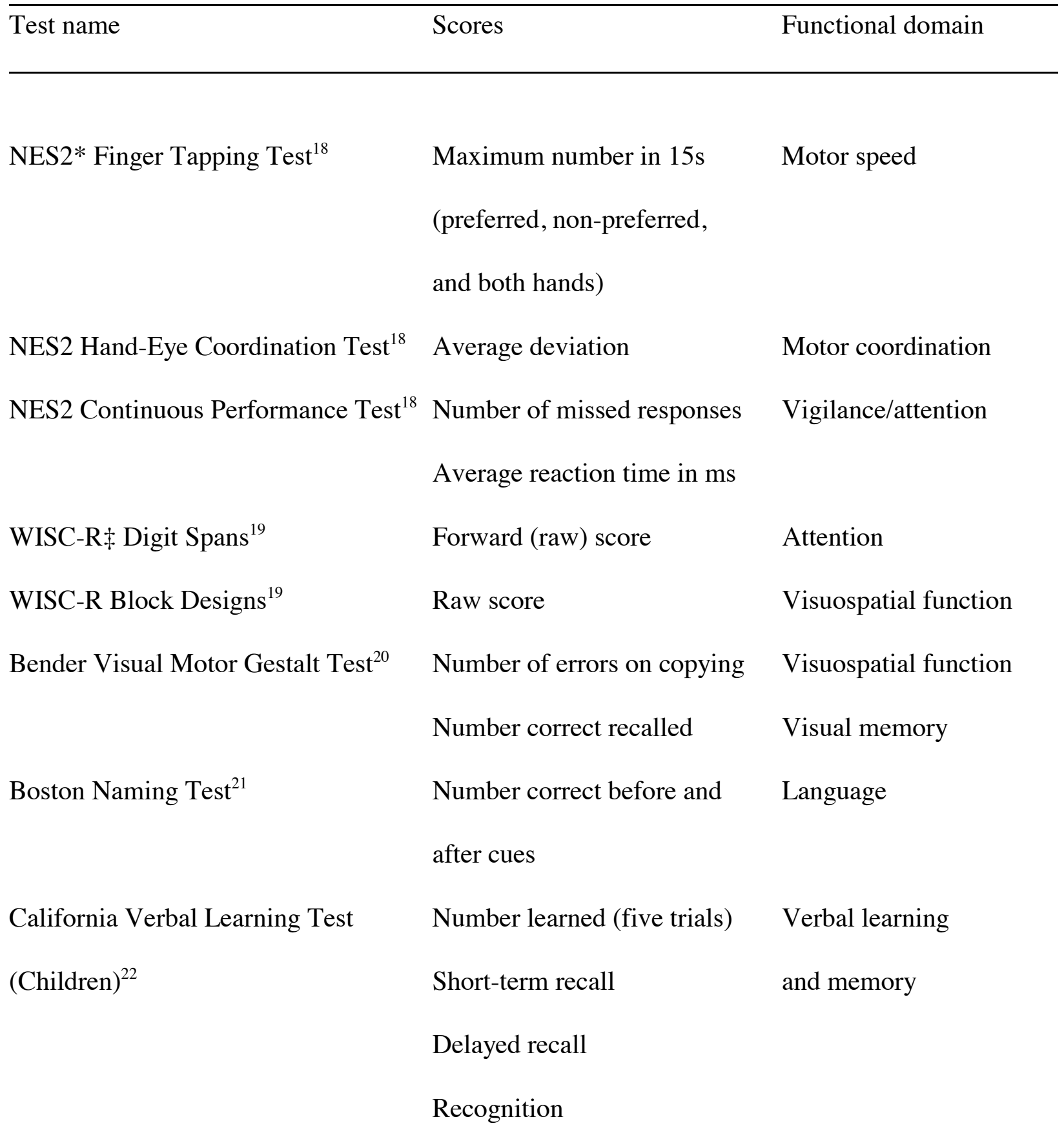

*Neurobehavioral Evaluation System 2

$\ddagger$ Wechsler Intelligence Scale for Children - Revised 
TABLE 2. Correlation between mercury exposure biomarkers

Correlation with hair

\begin{tabular}{lcccc} 
Biomarker & $n$ & Geometric mean & Proximal & Full-length \\
\hline Cord blood $(\mathrm{ug} / \mathrm{l})$ & 589 & 23.2 & 0.83 & 0.78 \\
Proximal hair $(\mu \mathrm{g} / \mathrm{g})$ & 602 & 4.61 & 1.00 & 0.93 \\
Full-length hair $(\mu \mathrm{g} / \mathrm{g})$ & 602 & 4.39 & 0.93 & 1.00 \\
\hline
\end{tabular}


TABLE 3. Confounder-adjusted regression coefficients (betas) for the logarithmic transformation of the cord-blood mercury concentration as predictor of neuropsychological test deficits in all children with complete data as compared to those where agreement between the two hair parameters suggested relatively stable exposures

All

Stable only

Test

Mean

$n$ Beta P value $n \quad$ Beta $\mathrm{P}$ value

NES2 Finger Tapping

Preferred hand 422

595

$-1.32$

0.049

537

$-1.45 \quad 0.050$

Other hand

40.5

596

$-0.71 \quad 0.268 \quad 538$

$-0.38 \quad 0.587$

Both hands

$54.1 \quad 592$

$-2.22$

$0.114 \quad 534$

$\begin{array}{ll}-1.96 & 0.202\end{array}$

NES2 Hand-Eye Coordination
Error score
2.62
591
$\begin{array}{lll}0.070 & 0.026 \quad 533\end{array}$
$0.076 \quad 0.025$

NES2 Continuous Performance Test

$\begin{array}{lrrrrrrr}\text { Missed responses }(\ln ) & 1.70 & 596 & 0.27 & 0.039 & 538 & 0.30 & 0.037 \\ \text { Reaction time } & 758 & 595 & 45.6 & <0.001 & 537 & 47.0 & <0.001\end{array}$

Wechsler Intelligence Scale for Children-Revised

$\begin{array}{lccccccc}\text { Digit Spans forward } & 3.8 & 587 & -0.33 & 0.056 & 530 & -0.32 & 0.098 \\ \text { Block Designs (squareroot) } & 3.8 & 586 & -0.20 & 0.124 & 529 & -0.28 & 0.058\end{array}$


Bender Visual Motor Gestalt Test

$\begin{array}{lccccccc}\text { Errors on copying } & 29.5 & 593 & 1.32 & 0.029 & 536 & 1.53 & 0.023 \\ \text { Reproduction } & 3.0 & 556 & -0.33 & 0.105 & 501 & -0.54 & 0.017 \\ & & & & & & & \\ \text { Boston Naming Test } & & & & & & & \\ \text { No cues } & 24.6 & 568 & -1.46 & 0.015 & 511 & -1.59 & 0.019 \\ \text { With cues } & 27.0 & 567 & -1.70 & 0.005 & 511 & -1.84 & 0.006 \\ \text { California Verbal Learning Test (Children) } & & & & & \\ \text { Learning } & 27.7 & 583 & -0.90 & 0.367 & 527 & -1.32 & 0.237 \\ \text { Short-term recall } & 3.9 & 577 & -0.63 & 0.039 & 521 & -0.90 & 0.009 \\ \text { Long-term recall } & 4.3 & 558 & -0.52 & 0.139 & 502 & -0.81 & 0.038 \\ \text { Recognition } & 10.5 & 552 & -0.14 & 0.547 & 497 & -0.20 & 0.450 \\ & & & & & & & \end{array}$

